\title{
ENTRE LA INMERSIÓN Y LA EXPLICACIÓN. LA DUALIDAD TRÁGICA EN EL TÚNEL DE ERNESTO SÁBATO ${ }^{1}$
}

\author{
BETWEEN IMMERSION AND EXPLANATION. \\ TRAGIC DUALITY IN ERNESTO \\ SABATO'S THE TUINEL
}

\author{
ENTRE A IMERSÃO E A EXPLICAÇÃO. \\ A DUALIDADE TRÁGICA EM O TÚNEL \\ DE ERNESTO SÁBATO
}

Wilfer Alexis Yepes Muñoz*

\section{RESUMEN}

Esta reflexión hunde sus raíces en las obras transicionales de Ernesto Sabato: Uno y el Universo y Hombres y engranajes, con elementos muy propios del mundo que instaura El túnel. Allí Juan Pablo Castel, encarna el túnel de su propia existencia desde dos puntos equidistantes y superpuestos: primero, la inmersión, que realiza como artista cuando pinta -una posibilidad que desafía toda lógica-, y segundo, la explicación, planteada como la necesidad de clarear una mujer inquieta y solitaria, frente a un mar tormentoso. Lo que permitirá comprender cómo Juan Pablo Castel

1 Este artículo deriva de la investigación de Doctorado en Filosofía que se intitula: Lo bumano como ficción. El pensamiento mágico de Ernesto Sabato. Línea de investigación: Estudios literarios.

* Doctor y Magíster en Filosofía, Filósofo y Licenciado en Filosofía y Letras por la Universidad Pontificia Bolivariana, sede Medellín. Se ha desempeñado como docente de cátedra en la Facultad de Filosofía de la universidad en mención. Su investigación se centra en la filosofía francesa del siglo XX, hermenéutica, estética y la relación filosofía-literatura.

Correo electrónico: waymes4@hotmail.com

ORCID: 0000-0001-5782-2732.

Artículo recibido el 7 de junio de 2016 y aprobado para su publicación el 9 de septiembre de 2016. 
caminará en dos direcciones necesarias, que no admitirán una síntesis: primero, la dirección yo-universo, que encaja en la necesidad de gobernar el mundo a partir de la abstracción, la urgencia de explicación de ese hombre profano que despierta de un sueño profundo; segundo, la dirección universo-uno en tanto búsqueda de lo humano, sin disminuir las contradicciones, ese largo ir y venir que no agota esas dos tendencias entremezcladas y ambivalentes.

\title{
PALABRAS CLAVE
}

Ernesto Sábato, Existencia humana, Inmersión, Explicación, Arte.

\begin{abstract}
The article is concerned with Ernesto Sabato's transitional works One and the Universe [Uno y el Universo] and Man and Mechanism [Hombres y engranajes] in relation to the distinctive features of The Tunnel [El túnel]. In the latter, Juan Pablo Castel embodies the tunnel of his own existence from the perspective of two equidistant and overlapped points: the immersion he performs as an artist when he paints -a possibility that challenges all logics- and the explanation, understood as the necessity to see through an uneasy and lonely woman. The previous elements might contribute to an understanding of the way in which Juan Pablo Castel moves towards two necessary directions that admit no synthesis. First, the direction me-universe that refers to the necessity to govern the world through abstraction and the pressing need to explain the profane man who wakes from a dream; second, the direction universe-one that refers to the quest for what is human, the coming and going that is not exhausted in these two intertwined and ambivalent tendencies.
\end{abstract}

\section{KEY WORDS}

Ernesto Sabato, Human Existence, Immersion, Explanation, Art.

\section{RESUMO}

Esta reflexão afunda suas raízes nas obras transicionais de Ernesto Sábato: Nós e o universo e Homens e Engranagens, com elementos próprios do mundo que $O$ Túnel instaura. Nesse romance, Juan Pablo Castel encarna o túnel de sua própria existência de dois pontos equidistantes e superpostos: primeiro, a imersão que realiza como artista quando pinta -uma possibilidade que desafia toda lógica-, e, segundo, a explicação, como a necessidade de clarear uma mulher inquieta e solitária diante de um mar tormentoso. Isso permitirá compreender como Juan Pablo Castel caminhará em duas direções necessárias, que não admitirão uma síntese: primeiro, a direção eu-universo, que encaixa na necessidade de governar o mundo a partir da abstração, a urgência de explicação desse homem profano que acorda de um sonho profundo. E, segundo, a direção universo-um como busca do humano, sem diminuir as contradições, esse extenso ir e vir que não esgota essas duas tendências misturadas e ambivalentes.

\section{PALAVRAS-CHAVE}

Ernesto Sábato, Existência humana, Imersão, Explicação, Arte. 


\section{Introducción}

$\mathrm{T}$

ras ser rechazado por un considerable número de casas editoriales en Buenos Aires, El túnel conoció la luz en 1948, gracias a un préstamo que Alfredo Juan J. Weiss ofreció a Ernesto Sabato (Constenla 313). Destacaremos en esta importante obra de las letras latinoamericanas dos elementos que mantendrán su tensión de principio a fin, y que constituirán la dualidad de Juan Pablo Castel, personajenarrador que encarna esa necesidad de explicación y de inmersión, en una relación asimétrica con su obra Maternidad, y María Iribarne, la única persona en ese mundo que se percató de la ventanita.

Castel transitará entre la inmersión que le proporcionará María en los fugaces pero profundos encuentros, y su necesidad de objetivación de esa escena inexplicable. Es llamado a caminar por su propio túnel: quizá cruce el umbral de la tensión que hay entre su obra y María -la inmersión del que crea; la inmersión del que, amando a una mujer como María, descubre el sentido oculto de su existencia- y la explicación: resolver una pregunta que irrumpe desde el fondo de su corazón. Aunque independiente de su autor, Castel se reconocerá en su obra, pintará porque desea saber algo de sí mismo.

Esta obra inicia con una confesión: "Bastará decir que soy Juan Pablo Castel, el pintor que mató a María Iribarne; supongo que el proceso está en el recuerdo de todos y que no se necesitan mayores explicaciones sobre mi persona" (El túnel 9). Castel no siente temor de anunciar su nombre, no esconde la mano, no guarda la motivación, la única que lo llevó a matar. No necesita que alguien más, aparte de él, hable del pensamiento que vivió en carne propia.

Es interesante que El túnel pretenda asumir el crimen², distanciándose de la pretensión objetiva de resolverlo. En ese sentido se diferencia de una

2 María Rosa Lojo piensa que El túnel puede ser una versión paródica de la novela policial: "El propio texto de El túnel podría ser visto así como una versión paródica (pero en su parodia, superadora de la convención) de la novela policial ortodoxa, transformada aquí en tragedia de la conciencia" (Lojo 44). 
novela policial, porque no aspira desvanecer una cuestión, siguiendo las huellas, explicando, trayendo a la luz en una jerarquía de evidencias todo lo ocurrido. Claro que Juan Pablo Castel oscila entre esa necesidad de síntesis y su doble movimiento del pensar: entre la inmersión y la explicación. Ya en 1945, Sabato oponía su opción por la literatura con la novela policial:

¿Qué significa explicar? Significa establecer una rigurosa cadena causal que termina en el crimen. El universo en que se mueven estos personajes está regido por leyes inexorables, donde no hay lugar para el milagro: es un universo estrictamente racional. Para que la novela cumpla con esta condición, se descartan deliberadamente los elementos irracionales o demoníacos que no se pueden plegar al esquema (Sabato, Uno 76).

Este es un universo estrictamente racional. El asesino es también el perseguido: "En este sentido, la novela policial ${ }^{3}$ científica presenta con claridad un problema de vasta trascendencia y es algo así como su reducción al absurdo: ces racional la realidad?" (Sabato, Uno 77). pensamiento lógico como base fundamental de los tiempos modernos corresponde a la dirección yo-universo -orientación cognoscitiva y explicativa-, si enmarcamos el análisis de las dos primeras partes de Hombres y engranajes en las reflexiones transicionales de Uno y el Universo. Siguiendo los postulados de Sabato, mudamos al hombre en objeto, tratamos de explicarlo mediante cadenas causales, que a primera vista parecen un rompecabezas, con la limitante de faltarle un número interminable de fichas. Esta operación implica depurar la narración de todo elemento irracional, porque prevalece la causalidad y el hambre de agarrar al asesino, de resolver el problema, antes que su vida, su memoria, su complejidad.

Lo que impulsa la explicación es el conocimiento como posesión de lo verdadero (Heidegger 386): agarrar lo agarrable, al asesino, archivarlo

3 La conversación sostenida entre la miope Mimí y Hunter, el primo de María Iribarne durante el capítulo XXV de El túnel, tiene como tema la novela policial: "-Mi teoría -explicó- es la siguiente: la novela policial representa en el siglo veinte lo que la novela de caballería en la época de Cervantes. Más todavía: creo que podría hacerse algo equivalente a Don Quijote: una sátira de la novela policial" (Sabato, El túnel 87). 
en la cárcel como un trofeo de la investigación lograda. En su análisis de la novela policial, Sabato trae a colación el desplazamiento vérités de fait-vérités de raison que Leibniz antepuso a la casualidad. Según Leibniz, todo tiene su raison d'être -principio de causalidad-, y esa razón de ser indica que el conocimiento debe configurarse a partir de las vérités de raison: "Y el ideal del conocimiento es el de ir reduciendo la masa caótica de las «vérités de fait» al orden divino de las «vérités de raison»" (Sabato, Tres aproximaciones 50).

La novela policial no difiere del acto persecutorio que caracteriza el pensamiento moderno pues hace un desplazamiento de lo no-conocido, de la oscura escena del crimen, a la solución de un problema: "Edgar Poe inventó ese relato estrictamente racional en que el detective no corre por los tejados sino que construye cadenas de silogismos; $y$ en que su criminal podría (y tal vez debería) ser designado por un símbolo algebraico" (Sabato, Tres aproximaciones 51). El pensamiento lógico es en este punto detective, investigador de algo, pericia de la razón que persigue las ideas. Cuando atrapa al culpable, al que culpan -no a quien se siente culpable, porque a primera vista Juan Pablo Castel se siente culpable ante algo previo-, encuentra las consecuencias esperadas de la indagación. El detective es un realizador de las vérités de raison: "El detective que convierte una multitud de hechos incoherentes en un riguroso esquema lógico-matemático, realiza el ideal leibniziano del conocimiento" (Sabato, Uno 77).

En nuestro plan de comprender -no como detectives esta obra de Sabato como doble movimiento de explicación e inmersión, consideramos conveniente aclarar que la crítica de Sabato a la novela policial se anticipa en Uno y el universo y se cristaliza en un personaje pretendidamente racional ${ }^{4}$ que termina destruyendo a la mujer -posibilidad de síntesis-

4 Recordemos la lectura psicoanalítica que Myriam Bustos y Raúl Torres realizaron en torno a Juan Pablo Castel: "Su intelecto permanece en constante ebullición. Nos impresiona cómo un hombre que ha pensado mucho y que para todo tiene ya una respuesta elaborada y fundamentada. Posee gran capacidad de abstracción y tiende al pensar lógico, aunque su lógica adolezca de caracteres demasiado personales. Su modo particular de razonar, distinto al normal, hace que las conclusiones que extrae sean también diferentes a las que sacaría de ellos un individuo corriente («la experiencia me ha demostrado -dice- que lo que a mí me parece claro y evidente, casi nunca lo es para el resto de mis semejantes»), razón por la cual consideramos este rasgo suyo como propio de los paranoicos, lo mismo que su desconfianza 
en quien deposita su comprensión: "Existió una persona que podría entenderme. Pero fue, precisamente, la persona que maté" (Sabato, El túnel 12). En esta obra, la primera de su corta pero intensa producción narrativa, pisamos un suelo distinto a la novela policial. El siguiente pasaje de El túnel instaura esa diferencia:

Pero cipor qué esa manía de querer encontrar explicación a todos los actos de la vida? Cuando comencé este relato estaba firmemente decidido a no dar explicaciones de ninguna especie. Tenía ganas de contar la historia de mi crimen, y se acabó, al que no le gustara, que no la leyese (Sabato, El túnel 12).

El primer gran acontecimiento, decir su nombre y confesar que mató a María Iribarne, hace de esta novela un desplazamiento del universo al yo, una especie de novela introspectiva, novela del yo. El segundo elemento, que emerge ligado al anterior, es la memoria. Recordemos también que en el horizonte de las vérités de fait, de las verdades de hecho, Juan Pablo Castel, ya encerrado, hace memoria no solo del asesinato, sino también de su vida como artista atormentado. En su pasado convergen su obra pictórica y su obra en María. Su memoria no es la de un optimista: no ha logrado lo que quería, en su pasado hormiguean las dudas más que la culpa; mejor aún, la culpa con una «duda irresoluble» que no resuelve su pensamiento alucinado:

En realidad, siempre he pensado que no hay memoria colectiva, lo que quizá sea una forma de defensa de la especie humana. La frase «todo tiempo pasado fue mejor» no indica que antes sucedieran menos cosas malas, sino que -felizmente- la gente las echa en el olvido. Desde luego, semejante frase no tiene validez universal; yo, por ejemplo, me caracterizo por recordar preferentemente los hechos malos y, así, casi podría decir que «todo tiempo pasado fue peor», si no fuera porque el presente me parece tan horrible como el pasado; recuerdo tantas calamidades, tantos rostros cínicos y crueles, tantas malas acciones, que la memoria es para mí como la temerosa luz que alumbra un sórdido museo de la vergüenza (Sabato, El túnel 9).

y su extrema sensibilidad hacia los que considera desdenes. Pese a que tiene la tendencia a estar continuamente razonando (en forma silogística, como ya pudimos anotar), no puede hacerlo con comodidad cuando hay alguien cerca. La presencia ajena le molesta, porque le impide pensar con tranquilidad" (Bustos \& Torres 312-313). 
Un primer elemento en este desplazamiento es la configuración del olvido como una especie de defensa de la humanidad. El hombre moderno es impulsado por la huida del centro, la negación de esa memoria de la unidad originaria, el desplazamiento uno-universo, que suprime la subjetividad en su complejidad inobjetivable. Incluso a menudo el pensamiento de Castel huye del centro, persiguiendo ese original sin atraparlo finalmente. Según Albert Fuss, Castel "Se va alejando cada vez más del objeto -es decir, de la realidad- que pretende analizar, lo cual es igualmente aplicable al análisis de su propia personalidad" (328). Castel es el lugar de ese doble movimiento del pensar. Cuando huye del centro mediante la lógica y la consiguiente urgencia de abstracción, está emparentado con el pensamiento extensivo y el conocimiento como posesión de lo verdadero. Se aleja del objeto porque su búsqueda no es de esa índole: la búsqueda del original no es la búsqueda del objeto. Es, por el contrario, la búsqueda del hombreen-el-mundo. Entonces destruye la obra, ese portal de significado, que pudiera acercarlo a la «atmósfera envolvente», incluyendo a María, ese componente femenino que permea esencialmente esa posible síntesis.

Claro que Castel se aleja de la realidad-objeto porque cree conveniente una dirección del pensar que no sacude en lo más mínimo un original inagarrable. En nuestra perspectiva, el pensamiento de Castel no está dividido, sino que adopta el movimiento del pensar que no es el adecuado para entrar en lo profundo de esa realidad que desafía su lógica. En primera instancia, como artista, Castel com-pone y colorea un portal que despierta su interés: allí podría estar recogido todo el sentido de su existencia. Pero una vez que la obra aparece en la distancia de la mirada -que no es una inmersión de las manos y de un rumor que todavía no parece real a los ojos-, lanza la lógica a conquistar la región inasible del sueño. Este movimiento lo aleja aún más de la síntesis, porque en él no hay inmersión, la finitud humana del saberse dentro. Y Castel no está completamente dentro: es pensamiento ciego, de la sola mirada.

La explicación tiene a las verdades de razón, aquellas que dudan metódicamente eliminando todo fait, en su travesía. Otra gran paradoja: el olvido del fait. La gran mayoría de esa gente de ciudad hace tumbas sobre sucesos que son muy personales y que no por eso se cierran en la 
persona de Castel. De algún modo Castel encarna esa resistencia a perder la ventanita. Paradójicamente con Castel también hacemos memoria, con su lienzo que es la historia perdida, la tablilla del recuerdo, el símbolo de un hombre pérdido. Él muestra su desacuerdo con aquellos hombres que no han visto la ventanita. Los críticos de arte pueden ser leídos en el horizonte del pensamiento casteliano (Sabato, El túnel 18) como la mirada de Medusa; serán los amnésicos racionales, aquellos notarios de la realidad que tienen su campo de visión en el ideal, las vérités de raison, mientras Castel y María enfocan su atención en la escena de la ventanita - en diminutivo, apenas perceptible al ojo del pensamiento lógico -, la ventanita-memoria, su vérité de fait. Ellos no son como los amnésicos que describe Cristina Peri: "Los amnésicos aseguran que es más fácil recordar el futuro que el pasado, en la medida en que los deseos se proyectan hacia adelante, y no hacia atrás" (16-17).

Lo segundo en esta memoria de lo pensado esta enmarcado en los «hechos malos». ¿Los hechos de Castel? ¿Esa humanidad que carga a sus espaldas un peso que no es suyo, que también puede ser de María y de los amnésicos racionales? En la ventanita, primeramente, esta la orientación de la memoria de Castel. Sería muy ingenuo de nuestra parte si pensamos que es el crimen, la culpa que desborda en el asesino, lo que condiciona su memoria de los «hechos malos». Comienza con su obra artística. Al final de este pasaje concluye: "[...] la memoria es para mí como la temerosa luz que alumbra un sórdido museo de la vergüenza" (Sabato, El túnel 9); temerosa luz, una luz tenebrosa donde convergen los opuestos (Lojo 111).

En la memoria emerge la visión como una dirección temerosa. Quizá no alumbra todo ese museo de vergüenza. Hace falta adentrar la memoria a lo irrealizado de la obra. En esta dirección, la memoria de Castel no tiene frente a sí un paisaje despejado y sereno. Tendríamos que involucrar en este punto la opacidad de la memoria. En este caso, el yo no puede agarrar su memoria como un objeto. Su memoria no es total y absoluta, no es ese mediodía que entra hasta los confines más apartados: "Mi cabeza era un pandemonio: una cantidad de ideas, sentimientos de amor y de odio, preguntas, resentimientos y recuerdos se mezclaban y aparecían sucesivamente" (Sabato, El túnel 47). 
Para profundizar en todas las provocaciones anteriores, es preciso que preguntemos: ¿Castel atraviesa el túnel? ¿Qué representa María en este tránsito? ¿El túnel comunica o separa? ¿En El túnel se fragua la irreconciliable dualidad «donde» camina el hombre? Proponemos que todas las insinuaciones anteriores converjan en dos puntos: uno que resolvimos llamar El drama de la soledad, que transita entre la explicación y la inmersión, desprendido de la obra de Castel y sus relaciones con María; y dos, La nostalgia del absoluto, la impotencia, lo irrealizable, que alcanza a Castel en todo momento. Para argumentar nuestro acercamiento, apelamos a algunas posturas afines - cuando lo consideremos conveniente - como la de María Rosa Lojo, Albert Fuss, Héctor Anabitarte, Pablo Sánchez, María Cecilia Graña y Juan Antonio Masoliver, por seleccionar unos cuantos entre la vasta lista de estudiosos de la narrativa de Ernesto Sabato.

\section{El drama de la soledad, que transita entre la explicación y la inmersión}

Concentremos nuestra atención en un binomio que apenas enunciamos en el punto anterior sin explicitar su alcance, y que dará lugar a esto que llamamos el drama de la soledad: el binomio memoria-olvido. Contrapusimos, en el horizonte del relato casteliano, la posición de los críticos de arte frente a su obra pictórica, porque eludieron la ventanita, elemento representativo que da sentido a esa memoria, a esa soledad de Castel. Para él, los críticos encarnan esa masa de hombres de ideas y teorías que han desdeñado la memoria en un mundo donde prevalece la abstracción y el olvido, la remoción de ese original, ese hombre concreto guillotinado en nombre de la Universalidad (Sabato, Tres aproximaciones 80). Para Sabato, el arte, el "gran arte», se presenta como transgresor de una «realidad estricta»; y vendría a su encuentro:

Todo gran arte es como un sueño, una reacción contra el mundo exterior, y en ocasiones una violenta y rencorosa negativa. Un gran creador levanta su obra porque le disgusta el mundo que lo rodea, malogrado por la fealdad, la imperfección, el relativismo y el desorden. El gran artista busca el absoluto. Su misterioso arte surge no sólo 
de la conciencia, sino, sobre todo, de los oscuros estratos de la inconsciencia, donde se revelan los instintos de la vida y de la muerte (Sabato, España 168).

La obra de Castel es admirada por los críticos. Pero esta admiración tiene una particularidad: esta obra forma parte de ese mundo externo codificado por leyes y teorías. Probablemente este motivo no agota la urgencia de presenciar ese absoluto que parece marginado a una ventana; ni siquiera una puerta, una ventana que solo permite un acceso a lo lejos. Según María Rosa Lojo: "La ventanita -como vidrio- ofrece una visión posible pero intocable, aislante de aquello que muestra" (Lojo 24). El arte presencia el absoluto como un ausente, un marginado, ya que camina a tientas como ciego-vidente, es testigo de un murmullo total, eso que María Rosa Lojo denomina como: "la Unidad pérdida, de un reino anterior a la erosión del límite y el tiempo" (Lojo 11).

Es preciso aclarar que esa ausencia y esa marginación están relacionadas con la necesidad de explicación de los críticos, que han privilegiado la visión. Sabato lo aclara: "Y tanto, porque la vista es el sentido más sutil, el más próximo al espíritu puro [...]" (Sabato, Tres aproximaciones 68). La visión del pensamiento lógico esta más próxima al espíritu puro. El arte como señal de ese camino es también ambivalente porque se convierte en ausencia-presente. En El túnel los críticos no han mirado, porque eludieron la ventanita, ese lanzamiento, esa imagen de la búsqueda, ese portal simbólico. En este sentido, la vista más próxima al espíritu puro refleja la ceguera del pensamiento lógico. El pensamiento lógico es un ciego que solo ve la abstracción; debe marginar, ahogar, guillotinar lo más próximo a la turbadora experiencia del yo.

Todo este panorama nos recuerda a Tiresias, ese doble juego de visión y ceguera, que habita en la mansión del Hades: "En seguida, ioh caudillo de pueblos!, vendrá el adivino que la ruta te habrá de decir y cuán larga ella sea y en qué modo el regreso hallarás sobre el mar rico en peces" (Homero, Odisea 10. 40). Ulises acude al adivino por indicación de Circe. Lo hace para que le indique la ruta de regreso a Ítaca. Para Carlos García Gual: "En el caso de Tiresias el ser escrutador de las indicaciones de las aves tiene un mérito especial, ya que, siendo ciego, necesita un 
previo observador de los signos que él luego interpreta" (Mitos 147). En su estudio sobre el Edipo rey de Sófocles, el mismo autor escribe: "La ceguera y también la vejez son rasgos de esta figura de enorme prestigio en la tradición poética" (Enigmático Edipo 93).

Si cotejamos el planteamiento sabatiano con este pasaje de la Odisea, encontramos dos posibles relaciones entre el ciego-vidente y el artista. La primera, ese doble juego de visión y ceguera. El artista busca el absoluto, es como un ciego a los ojos del que mira, ya que ha entrado a las profundidades del yo, a ese lugar primario y sin erosión de la memoria. El artista busca el absoluto donde los demás no han buscado; quizá porque huyen del absoluto, de ese tenebroso absoluto. Castel mismo huye cuando quiere comprender.

La segunda relación que podemos establecer entre esta figura oximorónica con el artista es el anuncio de la ruta: la búsqueda del artista sería como ese anuncio de la ruta. De hecho, Juan Pablo Castel no es solo el que busca, porque encuentra algo; también se pierde. Finalmente, deberá comprender que "ver no es tener (tocar) y contemplar no es vivir" (Lojo 24). En esta obra ese artista esta buscando todavía, parece que estaabandonando el pensamiento lógico, pero su travesía no ha pisado puerto seguro. Es que no hay puerto seguro ni punto fijo en esa «atmósfera envolvente»: hemos perdido esa universalidad de la sombra y en muchas ocasiones cuando parece que tocamos fondo, estamos explicando, tratamos de establecer los límites de ese reino inasible e inexplicable. Por eso el arte recurre a los símbolos. En este caso, la narrativa de Sabato acude al simbolismo de lo óptico de cara al optocentrismo del pensamiento lógico, a los ejes de una turbadora ambivalencia entre la ceguera y la visión:

No es el eje de la separación y la distinción, sino el de la turbadora ambivalencia. Por eso el simbolismo de lo óptico que traspasa toda la narrativa sabatiana muestra cuánta lucidez posible hay en la aparente privación de la vista, y cuánta insuperable oscuridad contamina la pretendida transparencia de la visión (Lojo 11).

El cuadro de Castel que se exhibe como la presencia imantada, la inmersión del logos, aparece como esa turbadora ambivalencia. Juan 
Pablo Castel da a conocer el escenario donde conoce a María Iribarne: "Todos saben que maté a María Iribarne Hunter. Pero nadie sabe cómo la conocí, qué relaciones hubo exactamente entre nosotros y cómo fui haciéndome a la idea de matarla" (Sabato, El túnel 13). En condición de detectives - esta no es nuestra intención -, podríamos inculpar a Castel de asesino. Él mismo lo hace cuando antepone su lógica a la descripción del cuadro. Creía conocerla, su relación con María no es únicamente la de un artista, sino la de un hombre pre-ocupado por la ventana. María aparece en su vida y en su obra en ese preciso momento en que todos los demás eluden la ventana. No se percatan de ella; quizá la mirada de los hombres esta de este lado, del manejo del color, de la simetría, de la com-posición. Prevalecerá incluso la «realidad estricta» del cuadro, a la «realidad profunda» que redime. La descripción del cuadro ex-puesto es para nosotros reveladora:

En el Salón de Primavera de 1946 presenté un cuadro llamado Maternidad. Era por el estilo de muchos otros anteriores: como dicen los críticos en su insoportable dialecto, era sólido, estaba bien arquitecturado. Tenía, en fin, los atributos que esos charlatanes encontraban siempre en mis telas, incluyendo "cierta cosa profundamente intelectual". Pero arriba, a la izquierda, a través de una ventanita, se veía una escena pequeña y remota: una playa solitaria y una mujer que miraba el mar. Era una mujer que miraba como esperando algo, quizá algún llamado apagado y distante. La escena sugería, en mi opinión, una soledad ansiosa y absoluta (Sabato, El túnel 13).

En ningún momento Castel desliga su obra de su vida. Esta obra es su vida, su túnel. Sabemos que el cuadro se llamaba Maternidad, pero su descripción solo enfatiza en una escena: la ventanita. Para los demás, profundamente intelectuales, se repetía el juicio del crítico en dos adjetivos que no afloran aquí por casualidad: sólido y arquitecturado; adjetivos que son para nosotros muy cercanos a la serenidad y la configuración de un sistema de referencia que tiene a los principios de la lógica como elementos reguladores de la abstracción. Una visión que no abraza esa complejidad ambivalente: no vieron lo que el artista vio al momento de crear, no hicieron memoria de esa condición antagónica y profunda de una realidad removida y ominosa: la ventanita, que estaba justo en la parte superior izquierda de la obra. Para Albert Fuss, "El artista había pintado 
en su cuadro, en la parte superior izquierda, la ventana a través de la cual se podía ver a una solitaria mujer mirando hacia el mar. La izquierda es el lado de lo inconsciente" (335).

El pensamiento no puede empuñar esa zona envolvente y oscura, ya que esta sumergido. No podemos agarrar esa realidad profunda del yo que ha desafiado el principio de no-contradicción, el determinismo (Sabato, Entre 91) que caracteriza al pensamiento lógico. Su principio es la ambivalencia (Lojo) o el entrecruzamiento 5 (Saer), las combinaciones arbitrarias que un esquema exclusivamente lógico devasta a favor de la universalidad: lo falso y lo verdadero, lo oscuro y lo luminoso, la ceguera y la visión.

La condición de esta escena del cuadro es la opacidad, la luz de la noche, un $\operatorname{mar}^{6}$ en movimiento y una mujer solitaria. Pero Castel remata esa descripción con una afirmación primordial para este punto de la reflexión: "Era una mujer que miraba como esperando algo, quizá algún llamado apagado y distante. La escena sugería, en mi opinión, una soledad ansiosa y absoluta" (Sabato, El túnel 13). Una mujer, el verbo mirar, ese símbolo óptico que en este caso denota distancia, porque va acompañado de dos componentes propios de esa opacidad: apagado, que sería no alcanzar a verlo completamente, corriente de sombras; distante, la mujer esta sentada del otro lado; no toca, no posee. Toda esta descripción sugiere una soledad ávida de atender al llamado, de acercarse; más aún, absoluta.

5 Para Juan José Saer, las ficciones particularmente obedecen al entrecruzamiento entre verdad y falsedad. Ese entrecruzamiento también es aplicable a la obra pictórica de Castel: "Por eso, no podemos ignorar que en las grandes ficciones de nuestro tiempo, y quizás de todos los tiempos, está presente ese entrecruzamiento crítico entre verdad y falsedad, esa tensión íntima y decisiva, no exenta ni de comicidad ni de gravedad, como el orden central de todas ellas, a veces en tanto que tema explícito y a veces como fundamento implícito de su estructura. El fin de la ficción no es expedirse en ese conflicto sino hacer de él su materia, moldeándola «a su manera»" (Saer 15).

6 Albert Fuss ahonda también en las especificidades de esta escena a partir del análisis de Jung: "Según Jung el mar, como símbolo del inconsciente colectivo, oculta bajo su superficie resplandeciente profundidades insospechadas (22). A través del encuentro con María, que encarna la parte femenina de su alma, Castel entra en conflicto con el lado oscuro de su personalidad. Con ello surge el peligro definido por Jung como sigue: «Conforme crece la influencia del inconsciente colectivo, la consciencia va perdiendo su poder director» (23). Es decir, Castel corre el riesgo de perder el control de sus actos" (Fuss 336). 
Decidimos nombrar este numeral El drama de la soledad porque llega un momento en la vida del hombre en que se reconoce ajeno a esas construcciones portentosas que deja atrás, pues se siente solo y llamado a la profundidad. Se trata de la soledad de un hombre entre máquinas, edificios y la lógica de la producción-consumo, la invalidez de un pensamiento que corre como loco respondiendo a un llamado insustituible que no admite más aplazamientos: Castel ha sugerido la soledad de esa mujer que se siente llamada y ansiosa de responder.

Llamada, la soledad llamada, ve en la distancia, oye ese rumor. Es un doble juego de ceguera y visión de la soledad. El elemento visionario sería el llamado ${ }^{7}$. María contempla esta escena como quien ha atendido un llamado y el cuadro incita a Castel a revivir su problema. Ahora tiene razones para buscar una explicación. En este paraje de la obra, Castel pretende iluminar, alcanzar y ahogar ${ }^{8}$ esa presencia inquietante de la escena con María. La atención de María, distinta a ese enfoque intelectual de la crítica, pone de relieve el elemento femenino que será despedazado, degradado a la condición de objeto (Fuss 333). Castel prácticamente persigue a María, busca a quien podría entenderlo. Albert Fuss piensa que: "El cuadro simboliza la experiencia vital de Castel: una racionalidad absorbente, siempre en primer plano, reprime el mundo inquietante de

7 Junto con el rumor, el ruido, el grito y la música, el llamado detenta una forma de conocimiento por el oído, la visión de la ceguera, según Lojo: "El llamado, a diferencia del grito, es -más que emitido por el sujeto- esperado o percibido secretamente desde su interioridad. Una cualidad semántica se impone sobre la física: la cualidad de mensaje significativo domina sobre la de cualquier particularidad sonora y genera una «clase» dentro del espectro auditivo. Pero ese significado suele resultar incomprensible" (Lojo 196).

8 Estos verbos tienen como sustrato a Castel, razonador: "Me sentía bastante tonto, de ninguna manera era esa mi forma de ser. Hice un gran esfuerzo mental, jacaso yo no razonaba? Por el contrario, mi cerebro estaba constantemente razonando como una máquina de calcular; por ejemplo, en esta misma historia ¿̨no me había pasado meses razonando y barajando hipótesis y clasificándolas? Y, en cierto modo, ¿no había encontrado a María al fin, gracias a mi capacidad lógica? Sentí que estaba cerca de la verdad, muy cerca, y tuve miedo de perderla: hice un enorme esfuerzo" (Sabato, El túnel 34-35). En otro fragmento del capítulo IX de El túnel, declara Castel: “ ¡No es que no sepa razonar! Al contrario, razono siempre. Pero imagine usted un capitán que en cada instante fija matemáticamente su posición y sigue su ruta hacia el objetivo con un rigor implacable. Pero que no sabe por qué va hacia ese objetivo, ¿entiende?" (Sabato, El túnel 35). 
lo inconsciente" (336). En una perspectiva similar, escribe María Rosa Lojo: "El cuadro, mensaje en su conjunto y no sólo en el fragmento, concluirá destrozado, sin culminar su proceso de exégesis, a manos de su propio autor" (24). La experiencia vital de Juan Pablo desemboca en la destrucción; esa falta de tocar, de agarrar, de comprender parece insoportable, se torna en angustia. Luego, esta dirección lógica sacrifica la experiencia doble del pensar que lo llevó a pintar ese recuerdo inagarrable.

No conocemos plenamente el yo de María, tenemos la perspectiva de Castel. Ella es un elemento tensor de esta complejidad donde camina el artista. Ella forma parte de un sueño que concluye con la destrucción del cuadro y su muerte. No obstante, si situáramos nuestra dirección de búsqueda del lado de María, optaríamos por plantear que ella firma su sentencia de muerte cuando se detiene en la escena de la ventana. Ella parece comprender:

Nadie se fijó en esta escena; pasaban la mirada por encima, como por algo secundario, probablemente decorativo. Con excepción de una sola persona, nadie pareció comprender que esa escena constituía algo esencial. Fue el día de la inauguración. Una muchacha desconocida estuvo mucho tiempo delante de mi cuadro sin dar importancia, en apariencia, a la gran mujer en primer plano, la mujer que miraba jugar al niño. En cambio, miró fijamente la escena de la ventana y mientras lo hacía tuve la seguridad de que estaba aislada del mundo entero; no vio ni oyó a la gente que pasaba o se detenía frente a mi tela (Sabato, El túnel 13).

Es indudable que debemos circunscribir a María Iribarne, la mujer, en esa periferia crepuscular de la ventanita; la prefiguración de una especie de original perdido, todo ello manifestado en la única persona que podía comprenderlo, o comprender esa síntesis ansiada de la obra. A este respecto dirá Héctor Anabitarte: "Juan Pablo se inventa otro en María, que contempla interesada, angustiada, la mujer frente al mar, en la tela. La contempla y se condena. Y Juan Pablo destruirá la tela, al otro que es el mismo" (320). 
Permitamos que en esta reflexión emerja una postura en esa lucha de fuerzas: María estaría del lado del artista-creador ${ }^{9}$, porque quizá en ella se materializa el cuadro cuando huye de Buenos Aires a la estancia, y contemplando la bravura de las olas en compañía de Castel, parece que la visión de la ventana se amplía, se aclara un poco, solo un poco. Para Pablo Sánchez, "[...] la mujer está más capacitada para el contacto con esa realidad misteriosa y tenebrosa que es irreductible a la razón" (92). María y el artista-creador podrían encarnar la síntesis, ese cuadro, esa Maternidad, la escena vivida:

Nos sentamos sobre las rocas y durante mucho tiempo estuvimos en silencio, oyendo el furioso batir de las olas abajo, sintiendo en nuestros rostros las partículas de espuma que a veces alcanzaban hasta lo alto del acantilado. El cielo, tormentoso, me hizo recordar el del Tintoretto en el salvamento del sarraceno (Sabato, El túnel 95).

Esta escena es para nosotros el movimiento tensivo del pensar de Castel: frente al mar, como la mujer solitaria que contemplaba a lo lejos un rumor, una tristeza y unas olas encrespadas como prolongación de esa desolación: "La tristeza fue aumentando gradualmente; quizá también a causa del rumor de las olas, que se hacía a cada instante más perceptible. Cuando salimos del monte y apareció ante mis ojos el cielo de aquella costa, sentí que esa tristeza era ineludible [...]" (Sabato, El túnel 95).

Este pensamiento emparentado con la finitud es un pensamiento vívido, que parece anular la pretensión de agarrar y de conocer claramente. El pensamiento de Castel no es aquí la Medusa que petrifica y lapida; lo vemos a oscuras, lo vemos humano. Esta escena también sugiere una soledad ansiosa y absoluta (Sabato, El túnel 13), la que recordó el

9 Distinguimos el artista-creador del artista-razonador. Juan Pablo Castel es un artista que ha presentado su obra, pero también razona esa relación estrecha que tiene su obra con su vida y sus deseos más profundos. En gran parte de esta novela encontramos al artista-razonador que termina siendo un incapaz que destruye lo que no puede comprender: el cuadro y María Iribarne. A este respecto dirá María Rosa Lojo: "Es posible también considerar estas escenas desde el punto de vista de la composición (el procedimiento de composición) de lo contemplado. Sólo en la primera oportunidad lo visto es producto del arte (un arte, desde luego, irracional, que no surge de la presunta "mente arquitectónica" de Castel, sino de impulsos profundamente efectivos, inconscientes)" (Lojo 28). 
artista cuando conoció a María - o el centro de atención de María -. Esta «atmósfera envolvente» de soledad evoca, por tanto, ese hombre-en-elmundo, incapaz de agarrar su tristeza, la opacidad de su yo; con una particularidad: María y él, aquella que en su atención podía rescatarlo de la soledad ${ }^{10}$. Contemplan, no dicen, están inmersos en ese paisaje que es coextensivo a su soledad. Por ello, la ventanita desafía la pretendida comprensión lógica. Esta es una ventanita inexplicable: no se hace ciencia con ella; se vive, se sufre:

Esa escena de la playa me da miedo -agregué después de un largo rato-, aunque sé que es algo más profundo. No, más bien quiero decir que me representa más profundamente a mí... Eso es. No es un mensaje claro, todavía, no, pero me representa profundamente a mí (Sabato, El túnel 36).

La obra es un deseo de síntesis que se actualiza y parece realizarse provisionalmente en esos encuentros intensos entre María y Juan Pablo. No pretendemos asumir una postura que dispense uno de esos elementos de la tríada artista-obra-crítico de esa postura que en la visión del narrador sofoca un elemento aparentemente periférico -la ventanita que trae hasta nosotros un horizonte primordial-. Consideramos que en la ventanita se tensa la lucha entre la explicación y la inmersión.

Ante una obra del hombre, podemos asumir el papel de notarios de la «realidad estricta» que aproximan su lupa para contrastar y constatar las vérités de raison. El otro camino a seguir sería, sin abandonar el pensar -porque Juan Pablo Castel es para nosotros un artista pensativo, que vive en carne propia su pensar-, existir al mismo tiempo que se piensa, esa necesidad de síntesis, a saber, el pensamiento en movimiento, la ficción, la posibilidad de lo humano en una obra que sacude y provoca como vérité de fait. El túnel remueve, remuerde, se ocupa y narra la memoria del original perdido. Esa ventanita pintada a la izquierda instiga, desajusta,

10 María parece salvarlo de la soledad: "Ahora que puedo analizar mis sentimientos con tranquilidad, pienso que hubo algo de eso en mis relaciones con María y siento que, en cierto modo, estoy pagando la insensatez de no haberme conformado con la parte de María que me salvó (momentáneamente) de la soledad. Ese estremecimiento de orgullo, ese deseo creciente de posesión exclusiva debían haberme revelado que iba por mal camino, aconsejado por la vanidad y la soberbia" (Sabato, El túnel 92). 
desmonta y des-compone la universalidad de las ideas claras y netas; inclina la visión de una «realidad estricta» a la ceguera visionaria de una «realidad profunda» donde se agita y acontece ese absoluto, ese original perdido.

\section{La nostalgia del absoluto}

A Castel se le escapa algo. Su soledad no es la situación que se aminora cuando María despunta como promesa cumplida de la ventanita. Una sola escena -la ventanita vivida que narra el capítulo XXV mientras ambos contemplan el mar furioso y la noche soberana- podría salvarlo de esa soledad. Pero esa soledad es absoluta. Coincidimos con María Rosa Lojo cuando afirma: "Pero la unión, la comunicación ansiada, no es concedida. Por el contrario la brecha entre ambos seres se hace más grave aún" (26). El punto de quiebre entre este encuentro de María y Castel en la estancia, y la temática de la soledad ansiosa y absoluta no concuerdan cabalmente. El desajuste estriba en el segundo adjetivo: absoluta. Si es absoluta, María tampoco puede salvarlo. De hecho, Castel se hace a la idea de que María lo engaña:

Mi cerebro funcionaba ya con la lúcida ferocidad de los mejores días: vi nítidamente que era preciso terminar y que no debía dejarme embaucar una vez más por su voz dolorida y su espíritu de comediante. Tenía que dejarme guiar únicamente por la lógica y debía llevar, sin temor, hasta las últimas consecuencias, las frases sospechosas, los gestos, los silencios equívocos de María (Sabato, El túnel 112).

Estas cavilaciones desembocan en una conclusión que nos permite entrever ese elemento absoluto como una constante en la obra: esta solo en el mundo, absolutamente solo y llamado irremediablemente por ese absoluto que pierde cada vez que razona. Las cartas de María no hacen más que comprobar - para él - ese desamparo, eso que falta: "No recuerdo ahora las palabras exactas de aquella carta, que era muy larga, pero más o menos le decía que me perdonase, que yo era una basura, que no merecía su amor, que estaba condenado, con justicia, a morir en la soledad más absoluta" (Sabato, El túnel 79). 
Esta soledad obedece a un razonar pretencioso que aleja a Juan Pablo del resto de los hombres. Soledad e incomunicación en esta obra son dos inconmensurables-inseparables. El artista-creador comunica su soledad. En cambio, ese mundo de hombres racionales se empecina en corroborar su representación del mundo -aislando, desfigurando y despilfarrando un universo que se escapa a esas costras de realidad, una realidad blindada con ecuaciones y panópticos-, y prefieren adjetivos como sólido y arquitecturado.

El artista lanza una señal mediante su obra como si esta fuera una composición mimética de esa situación real acogida por el pensamiento lógico: una ventanita casi que superpuesta pero nítida y real en su mostración espectral. Parece que ese lente nos permite reconocer que ese allá muy humano ha sido separado de este acá. Nos revela entonces la condición dual de una realidad humana que se debate entre la quietud del cielo platónico, acogida por el ilustrado y la tormenta de la caverna. Sería como mirar desde el exterior de la caverna, ver la luz, quedando ese espacio-tiempo diminuto e inauténtico a un lado, como un desecho. Nos inquieta esta transgresión, porque el cuadro de Castel evidencia no solo ese movimiento, ese ir y ese venir entre una dimensión y otra de nuestra propia condición. Nos esta señalando que ese otro fantasma olvidado lo vemos a lo lejos, o casi no lo vemos, porque nos interesa de este lado: la ciudad ${ }^{11}$, esa pretensión de

11 Para Renaud, escritores como Arlt, Marechal, Mallea, Onetti y Sabato introducen lentamente la temática urbana, que tiene como referente histórico, en el caso de Argentina, la independencia del Río de la Plata el 9 de julio de 1816. Comienza a realizarse un giro de la temática rural a la temática urbana; pero es decidido este movimiento en Roberto Arlt: "Mientras que la literatura latinoamericana de las décadas de 1920 y 1930 sigue siendo de inspiración en su mayor parte rural (Don Segundo Sombra, del argentino Güiraldes, se publica en 1926, Doña Bárbara, del venezolano Gallegos, en 1929; La vorágine, del colombiano Rivera, en 1924, y Huasipungo, del ecuatoriano Icaza, en 1934), Roberto Arlt se dedica resueltamente al universo urbano. Entonces se inicia una vertiginosa inmersión en un espacio hasta entonces pasado por alto o, por lo menos, desatendido por la creación novelesca argentina. Sin embargo, el camino trazado por el novelista, a pesar de las reticencias e incomprensiones que no dejan de suscitar su menosprecio a los tabúes más arraigados y ciertas audacias de lenguaje, es seguido por la mayoría. Sus compatriotas, y, de modo más general, los escritores del Río de la Plata, examinan con una sorprendente concordancia el universo de la ciudad. Toda una generación -Leopoldo Marechal (1900-1970), Eduardo Mallea (1903-1982), Ernesto Sábato (1911), el uruguayo Juan Carlos Onetti (1909-1994)se dedica en lo sucesivo a una minuciosa radiografía del mundo urbano" (Renaud 280). 
mundo inteligible. Pero esa ciudad es, paradójicamente, una Babilonia donde reina el movimiento, la inquietud de las sombras $-\mathrm{s}(\mathrm{h})$ ombra(e) s- que van de un lado a otro como seres platónicos que vuelven a entrar a la caverna. Toda una paradoja. Maryse Renaud aclara esta afirmación:

Percibida como una reencarnación de la antigua Babilonia, foco de
vicios y de depravación, recuerda también esa torre de Babel de las
Escrituras, en que reinan por completo la confusióny yla incomunicación.
Página tras página, el Buenos Aires de la década de 1930 adquiere un
verdadero perfil apocalíptico. Se vuelve esa megalópolis "tremenda",
"terrible", "agitada", "violenta"; en una palabra, es un universo
"monstruoso" que no puede engendrar más que horror (Renaud 285).

El hombre no parece encontrar un asidero para su soledad en medio del acero, la polución y ese tiempo que engulle su alma como un animal hambriento. Parece que ese gran monstruo donde pendula la soledad en instantes intensos de comunión, esa danza triste del tango que la hace introvertida y hasta introspectiva (Sabato, Tango 19), no abrevia esa liquidez, esa nulidad metafísica que caracteriza a ese hombre de ciudad, a Castel, el razonador solitario. Él huye constantemente de esa soledad marcada por el pensamiento lógico, esa luz artificial que ilumina los caminos sin salida de la angustia. Castel también observa a Buenos Aires por una ventana, como si se alejara:

Entonces respiré tranquilo; di unas vueltas por el corredor, fui hasta el extremo, miré el panorama de Buenos Aires por una ventana, me volví y llamé por fin el ascensor. Al poco rato estaba en la puerta del edificio sin que hubiera sucedido ninguna de las escenas desagradables que había temido (preguntas raras del ascensorista, etcétera) (Sabato, $E l$ túnel 28).

La temática urbana que demarca la narrativa latinoamericana a partir de Roberto Arlt, esta condicionada por la «realidad profunda». La ciudad es un estado del alma. El túnel, por ejemplo, no constituye un esfuerzo por describir el espacio urbano, aunque la acción narrativa se desarrolla mayormente en la ciudad de Buenos Aires. Allí Juan Pablo conoce a María; allí la busca. Sin embargo, en esta obra no abundan descripciones exhaustivas del espacio y cuando prorrumpen, son coextensivas al pathos 
de Castel. El espacio se intensifica, se entrecruza con la búsqueda; la ciudad termina siendo un lugar impreciso, sin salida, como las paredes de un laberinto al que estamos atados de pies y manos. No es propiedad de alguien, es un espacio siempre nuevo, desconocido como lugar común: Castel se siente como un forastero, como un extraño. La ciudad sería ese juego doble de lo subterráneo y lo abierto, lo privado y lo público, la calle y la casa, la oficina y el templo, el museo y el café, la soledad y la comunión ${ }^{12}$. Ese lugar donde reina la confusión y la angustia hace que los límites entre un elemento y su contrario sean difusos. La ciudad es el lugar de la tensión, de la dialéctica. Maryse Renaud hace una descripción de la ciudad como espacio-tiempo donde cohabitan los contrarios-inseparables:

La ciudad se ve insensiblemente dotada de una dimensión "subterránea" que prepara progresivamente el brote de la imagen infernal. Percibida a veces a través de sus espacios abiertos, y en otras ocasiones mediante sus lugares cerrados (hoteles, pensiones, cuartos amueblados, cafés, casas de cita), no deja de adoptar en toda ocasión los rasgos de un universo opresor (285-286).

Ese mundo es más complejo. Buscamos un asidero para nuestras promesas. Mientras nuestros ojos pueden percatarse de esa ciudad imparable que esta delante de nosotros, casi que ajena, estamos allí, cercados, de este lado. La ciudad esta en todas partes, en la ventana, en la oficina, en la agitación de hombres y mujeres anónimos que corren a sus trabajos. En ella también hay un deseo de restituir lo perdido, lo

12 El Informe sobre ciegos recuerda también esos mundos oscuros de las cloacas bonaerenses, aludiendo a lo sórdido, lo misterioso y oculto: "Noté, asimismo, que el piso no era ya horizontal sino que iba paulatinamente descendiendo, aunque sin ninguna regularidad, como si la galería hubiese sido excavada siguiendo las facilidades del terreno. En otras palabras, ya no era algo planeado y construido por ingenieros con la ayuda de máquinas adecuadas; más bien se tenía la impresión de estar en una sórdida galería subterránea cavada por hombres o animales prehistóricos, aprovechando o quizá ensanchando grietas naturales y cauces de arroyos subterráneos. Y así lo confirmaba el agua cada vez más abundante y molesta. Por momentos se chapoteaba en el barro, hasta que se salía a partes más duras y rocosas. Por los muros el agua se filtraba con mayor intensidad. La galería se agrandaba, hasta que de pronto observé que desembocaba en una cavidad que debía ser inmensa, porque mis pasos resonaban como si yo estuviera bajo una bóveda gigantesca. Lamentablemente, no me era posible vislumbrar siquiera sus límites a la escasísima luz que me daba mi encendedor" (Sabato, Sobre héroes 370). 
removido, lo líquido en el fondo de lo sólido. Nos referimos a la ventanita del cuadro. La inmersión, la memoria de lo pensado, de esa soledad absoluta y ansiosa, es la tablilla del recuerdo que permite unir la mirada de los dioses, esa mirada que crea y destruye, con nuestra mirada inquieta. María lanza una mirada a la ventana. Al parecer solo dos personas en ese mundo miran lo in-mirable, lo evitado, lo despreciado. Después, como dos mitades, se reúnen frente al mar y son como esa mujer del cuadro. Por ahora son el cuadro completo:

María y Castel, juntos frente al mar en la estancia de Hunter (Cap. XXVII) reúnen las dos mitades separadas del symbolon (en el sentido etimológico, señal partida, quebrada, por la cual cada uno de sus poseedores podía reconocer al otro). La unidad recompuesta, el rompecabezas armado por fin, la adivinanza resuelta, realiza y refleja a la vez los sueños de María (Lojo 26).

Pero en esta obra la síntesis se disuelve. La diluye el razonamiento obstinado del artista, que no puede comprender esa pérdida, ese momento irrepetible que requiere para apaciguar su angustia. María no es absoluta, no encaja completamente con ese ideal puro de Juan Pablo Castel y, por ende, tiene que matarla ${ }^{13}$. Además tiene que nihilizar esa opacidad propia que no comprende. Al parecer elimina lo que de él tiene María, esa inmersión, ese artista que al crear regresa al magma primordial. Sabato en uno de sus ensayos despliega la correspondencia ineludible entre la mujer y el arte:

Por otra parte, el arte es precisamente la creación del espíritu humano que más cerca se halla de lo femenino, porque en él no se ha producido esa escisión entre los diferentes elementos de la realidad, que se da en la ciencia o en la filosofía; lo concreto y lo abstracto, lo irracional y lo racional, permanecen indiferenciados. El artista es el hombre que más se aproxima a la unidad y, como tal, es un extraño monstruo, mitad hombre y mitad mujer, que tiene de aquel su capacidad para trascender la pura subjetividad, a la búsqueda de otros mundos, y de la mujer su

13 Sabato reconoce que el arte es expresión de feminidad, aquella que Castel aniquila: "Según Jung llevamos en nuestro inconsciente, más o menos reprimido, el sexo contrario. Si esta teoría es cierta, las creaciones más vinculadas a la inconsciencia, como la poesía y el arte, serían expresiones de su feminidad. Y, en efecto, ¿qué más femenino que el arte, aunque ( $o$ porque) sea realizado por hombres? El artista sería así una combinación de la conciencia y razón del hombre con la inconsciencia y la intuición de la mujer" (Sabato, Heterodoxia 54). 
tendencia a la unidad, a la permanencia en el magma primordial. La superación de la crisis ha de implicar, a la vez, una vuelta a la mujer $y$ al arte (Sabato, Heterodoxia 93).

En el arte, como en ninguna otra obra del hombre, se cumple el principio del entrecruzamiento de Saer y la ambivalencia de Lojo. La «realidad profunda» - de inmersión -acata ese doble juego de contrarios, promoviendo así una indiferenciación que la «realidad estricta» - de explicación - debe separar y delimitar. Ella misma comprende esa memoria, ese pensamiento vivido que no agarra, porque agarrar es sinónimo de separación, de límite y de negación de la realidad profunda donde el logos está inmerso en el mythos. Rafael Argullol trae hasta nosotros esa realidad profunda y concreta que Hölderlin hace decir a Hyperion: “ «Así el hombre se dio a sí mismo los dioses. Pues al principio el hombre y sus dioses eran una sola cosa y en ella, desconocida en sí misma, estaba la belleza eterna...» (III, 83)..." (268).

Juan Pablo se aproxima a la unidad; no la toca. Esta búsqueda parece sugerir esa mitad de sí mismo que representa María para él. Con esto indicamos que la mirada de María, esa que se aproxima a la ventana, es la ficha que falta. En Castel prevalece lo masculino, el pensamiento lógico, calculador, silogístico, centrífugo. De hecho, en El túnel no descubrimos a Castel pintando, aproximándose a esa unidad como artista-creador. Lo hace al final, encerrado. No está pintando, no esta ejerciendo esa actividad de síntesis mientras transcurre la obra; siempre esta abandonando esa aproximación a la unidad, huye del centro, corre a la estancia para encarnar esa unidad junto a María, en su tendencia a la unidad.

María esta más cerca a la unidad indiferenciada que él. Su mirada y sus cartas alcanzan esta tendencia: "He pasado tres días extraños: el mar, la playa, los caminos me fueron trayendo recuerdos de otros tiempos. No sólo imágenes: también voces, gritos y largos silencios de otros días ${ }^{14 "}$ (Sabato,

14 Sobre todo la segunda carta que María le escribe a Juan Pablo, que transcribimos completa: "He pasado tres días extrańos: el mar, la playa, los caminos me fueron trayendo recuerdos de otros tiempos. No sólo imágenes: también voces, gritos y largos silencios de otros días. Es curioso, pero vivir consiste en construir futuros recuerdos; ahora mismo, aquí frente al mar, sé que está y preparando recuerdos minuciosos, que alguna vez me traerán la melancolía y la 
El túnel 53). Toda su vida es como la escena de la ventana: huye siempre de la ciudad, se sienta a contemplar el mar, recuerda, hace memoria. Cuando María observa el cuadro de Castel, trae a su memoria todos esos recuerdos. No explica. Para ella es incluso extraño que Castel pretenda explicar y comprender todo. Coincide con él en la pintura. Parece que lo entiende, porque toda su vida es esa soledad. Pero Castel no da vuelta a la mujer y al arte. Por el contrario, destruye su obra y destruye a la mujer ${ }^{15}$.

Retomemos lo anterior. Castel es precisamente ese paisaje que debe asesinar una promesa incumplida. Encarna lo escrito por María Zambrano respecto al filósofo: "El filósofo vive hacia adelante, alejándose del origen, buscándose 'a sí mismo' en la soledad, aislándose y alejándose de los hombres" (98). Toda esta obsesión logocéntrica y centrífuga, ese deseo de saber que penetra con violencia y desgarra la realidad, se desplaza, se entrecruza con la obsesión de comprender ese mundo, alcanzado por la atmósfera envolvente, acuosa y nocturna de ese hombre-en-el-mundo. Castel es alcanzado por la sombra cuando busca una salida.

El cuadro de Castel descrito en la obra refleja también la Modernidad, ese deseo de conocer, una unidad perseguida. Pero una Maternidad que ha puesto la ventanita en un segundo plano como un acontecimiento insignificante. El pasado, la memoria, están a un lado; se velan en una opacidad que no nos permite entrar con los ojos de la lógica; no es reconocida, comprendida. Juan Pablo solo describe la parte más terrible de su obra. Recordemos también que la visión de los críticos nos brinda otra perspectiva. De este lado, la ventanita es lo eludido, ya que predomina

desesperanza. El mar está ahí, permanente y rabioso. Mi llanto de entonces, inútil; también inútiles mis esperas en la playa solitaria, mirando tenazmente al mar. ¿'Has adivinado y pintado este recuerdo mío o has pintado el recuerdo de muchos seres como vos y yo? Pero ahora tu figura se interpone: estás entre el mar y yo. Mis ojos encuentran tus ojos. Estás quieto y un poco desconsolado, me miras como pidiendo ayuda. MARÍA" (Sabato, El túnel 53).

15 Albert Fuss hace una interpretación similar a la nuestra: "En las relaciones entre María y Castel muy pronto se descubre que el lado femenino de Castel, su ánima, se ha quedado en estado embrionario frente a su lado masculino. El ánima del protagonista posee predominantemente los rasgos de la madre, es decir, Castel no ha superado todavía una primera etapa de su individuación" (336). 
la maternidad, el abrazo sereno de la madre ideal ${ }^{16}$. El proyecto moderno acoge como una madre -que no está en ningún lado y en todos-, es envolvente, embota, estabiliza, plastifica y petrifica nuestra condición: una maternidad progresiva y enfermiza que termina devorándonos.

María es un objeto anulado por Castel, ese vaso lleno de intenciones que se derraman hasta convertirlo en un loco de este lado. A este respecto, Juan Antonio Masoliver piensa que: "Castel no es castigado por la sociedad por un crimen, sino que es declarado loco y se le encierra en un manicomio, lugar más indicado para los artistas que las cárceles, adonde van los asesinos sensatos y cuerdos" (268). De ese otro lado, Juan Pablo es un hombre solitario.

Pese a esa referencialidad lógica, es la Odisea del que se sabe incapaz de regresar a Ítaca, porque la comunicación con ese fuera de la ventana se ha roto: vemos moverse algo a lo lejos. Únicamente vemos, porque de este lado solo aprendimos a ver. Castel es la lucha de fuerzas, la ficción como búsqueda de un puente que nos comunique con nosotros mismos, este despeñadero del alma que ve como falso lo que la literatura tiene para decirnos del hombre. Esta Babilonia es entonces el manicomio de los normales racionales. A locos como Castel hay que encerrarlos, aunque no encierran su mirada: la mirada es también como un pájaro que nos lleva y nos trae desde el mundo hasta nosotros. Después se vuelve serpiente, animal que se arrastra entre sombras y luces artificiales que alumbran a medias.

16 María Rosa Lojo analiza la relación entre la madre y María, aunque con una serie de variantes: "Por lo demás, la imagen de la mujer sola (que no es tampoco un paradigma convencional de belleza o de juventud) se instala en una relación diafórica con la figura plena, integrada en una ancestral tradición, de la Madre y el Niño. La actitud ansiosa y generadora de ansiedad perturba o contradice la paz del ícono sacralizado, la armonía de la destinación femenina socialmente aceptada y legítima. Se anuncia aquí la peligrosa divergencia entre María Iribarne (la mujer sexualmente experimentada, adúltera, pecadora) y la imago religiosa del dogma mariano (la Inmaculada, sin pecado concebido, virgen y madre de un Hijo que redimirá el mundo). Este quiebre entre las dos imágenes exhibidas, que les impide superponerse, esta forzosa distancia (de la perfección arquetípica a la condición carnal, de lo absoluto a lo relativo) trastornará a Castel, incapaz de aceptar la diferencia, de dejarlas coexistir y, menos aún, de integrarlas" (Lojo 24). 
Castel anuncia sin comprender; su memoria criminal nos recuerda una promesa, una búsqueda sin síntesis, una dialéctica que se paraliza antes de alcanzarla, el desenlace soñado y progresivo de la razón moderna. Castel anuncia su libertad, su yo desgarrado. En esta situación resuena esa nada, ese llamado a la libertad, la lejanía que nos pasa su cuota cuando parece que hemos completado una parte de ese ser nuestro que creemos próximo. En la vida de Juan Pablo Castel se cumple la indisoluble correlación libertadnihilización, que profundiza magistralmente Sartre en El ser y la nada:

La libertad, en efecto, como lo demostramos en el capítulo anterior, es rigurosamente asimilable a la nihilización: el único ser que puede ser llamado libre es el ser que nihiliza su ser. Sabemos, por lo demás, que la nihilización es carencia de ser, y no podría ser de otro modo. La libertad es, precisamente, el ser que se hace carencia de ser (Sartre 766).

La libertad no puede equipararse a lo conocido. De hecho, esa orientación racional del pensamiento de Castel, ya no como artista-creador, sino como razonador que busca una explicación para esa ventanita inexplicable y que se rompe en el preciso momento en que María comienza a desarticularse con la mujer de la escena pintada, hace de esa búsqueda de conocimiento una angustia ante su propia nada. Toda la travesía que conduce de la ventanita al asesinato de María refleja la nihilización de su propio ser, de aquello que no reconoce siendo inherente a su obra, a esa memoria de lo pensado que rebasa su pensar, tocando hasta el fondo su propia finitud. Renuncia, por tanto, a la síntesis, actúa como quien destruye la promesa de allanar y de dar respuesta a su propia vérité de fait.

En El túnel nos topamos precisamente con esa condición de la libertad que cosifica todo a su paso; da razones, se arma de ellas para encontrar un sentido, pero termina atrapada en su propio atrapamiento. Sin embargo, no es anulada la síntesis de la ventanita, sino que queda aplazada en tanto síntesis. Castel está solo, ansiosa y absolutamente solo. María no puede salvarlo de esa soledad que él no puede comprender. Esto explica por qué su necesidad de María se transforma en persecución; y para estabilizar lo incomprensible, para dejar de ese lado una vérité de fait, al convertirla en vérité de raison, tiene que matarla. Entonces, pierde la síntesis. Sartre sitúa la libertad del lado de la soledad: 
En tal sentido, podemos llamar al conocimiento la pura soledad de lo conocido. Es decir, con suficiente claridad, que el fenómeno original de conocimiento no agrega nada al ser y nada crea. Por él, el ser no es enriquecido, pues el conocimiento es pura negatividad: hace solamente que haya ser. Pero este hecho de "que haya" ser no es una determinación interna del ser -que es lo que es-, sino de la negatividad (258).

En lugar de sentirnos en casa y de encontrar las consecuencias agradables de lo conocido, como si todo eso agregara algo a esa nada que hace que haya ser, el conocimiento es la soledad de lo conocido. Los sentimientos del artista de El túnel no distan de esta soledad pura de lo conocido. Solo conoció a María; pudo petrificar esa condición insustituible que la hacía alguien para él. María solo agregó algo cuando él sintió que en sus brazos toda la comprensión se extendía y disminuía por esos instantes intensos de su soledad. La escena frente al mar no puede explicarla en ese instante. Su pensamiento ha entrado en lo profundo, es pensamiento de inmersión momentáneo. Pero al salir, todo cambia: mira a María en la distancia, está enceguecido por su afán de explicarlo todo. En efecto, su conocimiento es pura negatividad, nunca se siente en casa. Y el encuentro frente al mar no hace más que evocar su vértigo del acantilado, detallado bellamente en el capítulo XXVII:

Yo no decía nada. Hermosos sentimientos y sombrías ideas daban vueltas en mi cabeza, mientras oía su voz, su maravillosa voz. Fui cayendo en una especie de encantamiento. La caída del sol iba encendiendo una fundición gigantesca entre las nubes del poniente. Sentí que ese momento mágico no se volvería a repetir nunca. «Nunca más, nunca más», pensé, mientras empecé a experimentar el vértigo del acantilado y a pensar qué fácil sería arrastrarla al abismo, conmigo (Sabato, El túnel 96).

No decía nada. Todo su pensamiento parecía encantado por una síntesis entre la escena de la ventanita y su soledad ansiosa. Todo su ser rebosa de sentimientos e ideas sombrías, expresiones claras de inmersión. El encantamiento puede significar ese pensamiento vivido que pintó Juan Pablo en Maternidad y que ahora se actualiza en el abrazo sobrecogedor de María. Pensamos que en esta primera parte, Castel es un hombre centrípeto ingresando a su «realidad profunda», su propia opacidad, 
su propia síntesis: "Mi pensamiento flotaba como un corcho en un río desconocido" (Sabato, El túnel 101). En este caso su pensamiento flota abrazado por la memoria que prorrumpe en la inmersión. No puede agarrar, lapidar. El abrazo de María es como un río desconocido, y su pensamiento, un corcho insignificante, cargado de sentimientos e ideas oscuras. Ese movimiento es equiparable al vértigo que experimentan Tomás y Teresa en La insoportable levedad del ser:

Aquel que quiere permanentemente "llegar más alto" tiene que contar con que algún día le invadirá el vértigo. ¿Qué es el vértigo? ¿El miedo a la caída? Pero ćpor qué también tenemos vértigo en un mirador provisto de una valla segura? El vértigo es algo diferente del miedo a la caída. El vértigo significa que la profundidad que se abre ante nosotros nos atrae, nos seduce, despierta en nosotros el deseo de caer, del cual nos defendemos espantados (Kundera 65).

María y Juan Pablo se fundieron por unos instantes con el paisaje sombrío de las olas inquietas y de la noche. Luego pensó y sintió vértigo del acantilado, del abismo. Este vértigo que llamaremos vértigo de las profundidades trae consigo dos posibilidades: lanzarse con ella completamente, anular la posibilidad, o escapar como loco. No es un miedo a la caída, sino a la profundidad que se abre ante ellos. Luego, Castel no puede atravesar el túnel.

\section{Conclusiones}

Ese túnel personal, sin María, es para nosotros el lugar de la oscilación, de un pensamiento vivido que se sabe incapaz de luz y de cercanía. Por ello, como Sartre, vinculamos el conocimiento con la soledad de lo conocido y la negatividad que no agrega nada a la libertad. Conociendo estamos huyendo de esa inmersión definitiva del pensamiento explicativo. Mientras el hombre existe no puede refugiarse definitivamente en uno de esos movimientos: en la explicación o la inmersión. Ese túnel sería la existencia misma en ese ir y venir, la oximorónica experiencia de explicar y sumergirse sin explicar ni sumergirse totalmente. El vértigo del acantilado engendra en Castel esa prisa de volver a la ciudad para comenzar de nuevo. 
De regreso a Buenos Aires, Castel comienza a intentar una explicación a la ausencia de María. Llama por teléfono y amenaza con suicidarse ${ }^{17}$. Ambos acuerdan encontrarse, pero ella decide quedarse en la estancia: "En cuanto salí al camino a Mar del Plata, lancé el auto a ciento treinta kilómetros y empecé a sentir una rara voluptuosidad, que ahora atribuyo a la certeza de que realizaría por fin algo concreto con ella" (Sabato, El túnel 122).

Luego de concluir que María no puede salvarlo de su soledad, Juan Pablo se lanza como un loco, destruyendo primero el cuadro (Sabato, El túnel 118) y poniendo toda su atención en la escena de la ventanita hecha añicos. Ha destruido el pasaje de su túnel. Finalmente, en este tránsito, María queda reducida a objeto. El cuchillo de Castel rasga la piel de María como un lienzo que también debe destruir. Comprendemos, por tanto, que en El túnel se fragua la irreconciliable y trágica dualidad «donde» camina el hombre:

\begin{abstract}
No, ni siquiera ese muro era siempre así: a veces volvía a ser de piedra negra y entonces yo no sabía qué pasaba del otro lado, qué era de ella en esos intervalos anónimos, qué extraños sucesos acontecían; y hasta pensaba que en esos momentos su rostro cambiaba y que una mueca de burla lo deformaba y que quizá había risas cruzadas con otro y que toda la historia de los pasadizos era una ridícula invención o creencia mía y que en todo caso había un solo túnel, oscuro y solitario: el mío, el túnel en que había transcurrido mi infancia, mi juventud, toda mi vida. Y en uno de esos trozos transparentes del muro de piedra yo había visto a esta muchacha y había creído ingenuamente que venía por otro túnel paralelo al mío, cuando en realidad pertenecía al ancho mundo, al mundo sin límites de los que no viven en túneles; y quizá se había acercado por curiosidad a una de mis extrañas ventanas y había entrevisto el espectáculo de mi insalvable soledad, o le había intrigado el lenguaje mudo, la clave de mi cuadro (Sabato, El túnel 122-123).
\end{abstract}

17 Algo se rompió entre María y Juan Pablo: "Desesperado, salí a buscarla por todas partes, es decir, por los lugares en que habitualmente nos encontrábamos o caminábamos: la Recoleta, la Avenida Centenario, la Plaza Francia, Puerto Nuevo. No la vi por ningún lado, hasta que comprendí que lo más probable era, precisamente, que caminara por cualquier parte menos por los lugares que le recordasen nuestros mejores momentos. Corrí de nuevo hasta su casa, pero era muy tarde y probablemente ya hubiera entrado. Telefoneé nuevamente: en efecto, había vuelto; pero me dijeron que estaba en cama y que le era imposible atender el teléfono. Había dado mi nombre, sin embargo. Algo se había roto entre nosotros" (Sabato, El túnel 74). 
El túnel de la existencia se tensa entre esa necesidad de síntesis y la soledad de lo conocido. Castel estaba solo, porque el destruir a María orienta esa reducción a la certeza de que ella no podía salvarlo de su soledad. Para él, ella vivía como los demás: sin túneles. Su soledad insalvable está ligada, por tanto, a un túnel, y María, la que está de ese otro lado, en ese mundo, en esa síntesis, no puede entrar a su doble movimiento de creación y nulidad. No podemos, en efecto, echar en saco roto estas intuiciones que despliegan lo humano de una heroicidad como corcho en un río desconocido. Frente a ese mar de conocimientos y queriendo ser comprendidos, queriendo obsesivamente, la repetición del tipo ${ }^{18}$ hace ver a los artistas como locos. Castel es un loco visionario. Esta obra revela la incompatibilidad de lo silogístico, esa lógica de hierro (Sabato, El túnel 29), con lo absurdo de la existencia; silogismos, en gran medida, absurdos, nocturnos, que no agarran de modo suficiente un comportamiento: "Hice repetidos esfuerzos para colocarlas en el orden debido, hasta que logré formular la idea en esta forma terrible, pero indudable: María y la prostituta han tenido una expresión semejante; la prostituta simulaba placer; María, pues, simulaba placer; María es una prostituta" (Sabato, El túnel 112).

Lo humano es esa búsqueda sin síntesis, esa nada, ese movimiento nadificador. De ahí el vínculo de El túnel con el existencialismo (Gadsby 27). Es, por tanto, una fisura con ese mundo cercado por la Medusarazón. La literatura des-compone la im-posición, re-componiendo la memoria de lo pensado: esa dualidad fatídica. Y no tiene que ser optimista con el hombre, porque no agarra lo humano. Se limita más bien a tantear a partir de esos movimientos. En suma, Juan Pablo soporta su soledad y su imperfección, su nostalgia del absoluto: "A pesar de todo, el hombre tiene tanto apego a lo que existe, que prefiere finalmente soportar su imperfección y el dolor que causa su fealdad, antes que aniquilar la fantasmagoría con un acto de propia voluntad" (Sabato, El túnel 75).

18 Castel aborrece la generalidad del tipo: "Diré antes que nada, que detesto los grupos, las sectas, las cofradías, los gremios y en general esos conjuntos de bichos que se reúnen por razones de profesión, de gusto o de manía semejante. Esos conglomerados tienen una cantidad de atributos grotescos, la repetición del tipo, la jerga, la vanidad de creerse superiores al resto" (Sabato, El túnel 16). 


\section{Lista de referencias}

Anabitarte Rivas, Héctor. "Un solo túnel oscuro y solitario”. Cuadernos hispanoamericanos. 391-393 (1983): 320-323.

Argullol, Rafael. El héroe y el único. Barcelona: El Acantilado, 2008.

Bustos Arratia, Myriam y Torres Martínez Raúl J. "Juan Pablo Castel, entre la neurosis y el crimen". Cuadernos hispanoamericanos. 391-393 (1983): 282-315.

Chavarri, Raúl. "La metafísica o las metafísicas de Ernesto Sábato". Cuadernos hispanoamericanos. 391-393 (1983): 675-680.

Constenla, Julia. Sábato, el hombre. La biografía definitiva. Buenos Aires: Sudamericana, 2011.

Fuss, Albert. "El túnel, universo de incomunicación". Cuadernos hispanoamericanos. 391-393 (1983): 324-339.

Gadsby, Arlete. La influencia del existencialismo en las novelas de Sábato. Tesis de Maestría en Artes. Vancouver: The University of British Columbia, 1980.

García Gual, Carlos. Enigmático Edipo. Mito y tragedia. Madrid: Fondo de Cultura Económica, 2012. . Mitos, viajes, héroes. Madrid: Fondo Cultura Económica, 2011.

Givone, Sergio. Historia de la nada. Trad. Alejo González y Demian Orosz. Buenos Aires: Adriana Hidalgo, 2001.

Heidegger, Martin. ¿Qué significa pensar? Trad. Raúl Gabás. Madrid: Trotta, 2005.

. Nietzsche. Trad. Juan Luis Vermal. Barcelona: Ariel, 2014.

Homero. Odisea. Trad. J. M. Pabón. Madrid: Gredos, 2006.

Kundera, Milan. La insoportable levedad del ser. Trad. Fernando Valenzuela. Barcelona: TusQuets, 2010.

Lojo de Beuter, Maria Rosa. Sábato: en busca del original perdido. Buenos Aires: Corregidor, 1997.

Masoliver, Juan Antonio. "El túnel a manera de prólogo". Cuadernos hispanoamericanos. 391-393 (1983): 259-281.

Peri Rojas, Cristina. Cosmoagonías. Barcelona: Juventud, 1994.

Renaud, Maryse. "La novela urbana y psicológica (Arlt, Marechal, Mallea, Onettu, Sábato)". Historia de la cultura literaria en Hispanoamérica II. Ed. Puccini, Darío y Yurkievich, Saúl. Trad. 
Juan Carlos Rodríguez Aguilar, Eliane Cazenave y Beatriz González Casanova. México: F.C.E., 2010. 277-316.

Sabato, Ernesto. Antes del fin. Bogotá: Seix Barral, 2004. . Apologías y rechazos. Bogotá: Seix Barral, 2001. . El escritor y sus fantasmas. Barcelona: Booket, 2004. . El túnel. Bogotá: Booket, 2012. . Entre la letra y la sangre. Conversaciones con Carlos Catania. Bogotá: Seix Barral, 2003. . España en los diarios de mi vejez. Buenos Aires: Seix Barral, 2004.

. Tres aproximaciones a la literatura de nuestro tiempo: RobbeGrillet, Borges, Sartre. Santiago de Chile: Universitaria, 1968.

. La cultura en la encrucijada nacional. Buenos Aires: Sudamericana, 1976. . La resistencia. Bogotá: Seix Barral, 2011.

. Obras Ensayos. Buenos Aires: Losada, 1970.

- Tango. Discusión y clave. Buenos Aires: Losada, 2005.

. Sobre héroes y tumbas. Buenos Aires: Seix Barral, 2006.

. Hombres y engranajes. Buenos Aires: La Nación, 2006.

. Uno y el Universo. Buenos Aires: La Nación, 2006.

. Heterodoxia. Buenos Aires: Seix Barral, 2011.

Saer, Juan José. El concepto de ficción. Buenos Aires: Seix Barral, 2004.

Safranski, Rüdiger. El mal o el drama de la libertad. Trad. Raúl Gabás. Barcelona: TusQuets, 2005.

Sánchez, Pablo. El método y la sospecha. Estudios sobre la obra de Ernesto Sabato. Madrid: ArCiBel, 2010.

Sartre, Jean-Paul. El ser y la nada: Ensayo de ontología fenomenológica. Trad. Juan Valmar. Buenos Aires: Losada, 2008.

Sturniolo, Norma. "El símbolo de la mujer en Ernesto Sábato". Cuadernos hispanoamericanos. 391-393 (1983): 653-661.

Zambrano, María. Filosofía y poesía. México: F.C.E., 2010. 